HELMINTHOLOGIA, 53, 2: 155 - 160, 2016

\title{
Presence of Meloidogyne enterolobii on Jalapeño pepper (Capsicum annuum L.) in Sinaloa, Mexico
}

\author{
E. VILLAR-LUNA ${ }^{1, a}$, O. GOMÉZ-RODRIGUEZ1', R. I. ROJAS-MARTíNEZ1', E. ZAVALETA-MEJÍA ${ }^{1 *}$
}

${ }^{1}$ Programa de Fitopatología, Colegio de Postgraduados-Campus Montecillo, km 36.5 Carretera México-Texcoco, Texcoco, Estado de México, 56230, México. *E-mail: zavaleta@colpos.mx; aPresent address: Instituto Politécnico Nacional, CIIDIR-IPN Unidad Michoacán. Justo Sierra 28, 59510, Jiquilpan, Michoacán, México

Article info

Received June 23, 2015 Accepted September 17, 2015

\section{Summary}

Meloidogyne enterolobii $(\mathrm{Me})$ is an emerging root-knot nematode (RKN) and the most important worldwide for its high aggressiveness and increasing geographical distribution. In Mexico only in watermelon and tomato has been reported. Here we report the presence of this nematode in Jalapeño pepper collected in the state of Sinaloa. The morphological and morphometric characteristics of the second-stage juveniles and adult females were similar to those described for Me. DNA sequencing and alignment analysis (BLAST/GenBank) showed that the SCAR and rDNA IGS2 fragments had a $99 \%$ of identity, with Me DNA sequences present in the database. The results obtained indicate that the RKN detected corresponds to M. enterolobii. To our knowledge, this is the first report of this nematode in chilli pepper in this region of Mexico, considered of major economic importance for the variety of vegetables grown and the extension of the area sown.

Keywords: Meloidogyne mayaguensis; PCR; sequence-characterized amplified region; intergenic spacer region; root-knot nematodes

\section{Introduction}

Root knot nematodes (RKNs) are economically the most important by the great losses they cause in crop yields. Over 90 species (Meloidogyne spp.) attacking more than 3000 species of plants have been described (Adams et al., 2009). The most important and widespread species are Meloidogyne incognita (Kofoid and White, 1919) Chitwood, 1949; M. arenaria (Neal, 1889) Chitwood, 1949; and M. javanica (Treub, 1885) Chitwood, 1949; however, currently M. enterolobii Yang and Eisenback, 1983 (=M. mayaguensis Rammah and Hirschmann, 1988) has become more important worldwide for its high aggressiveness, increasing geographical distribution and wide host range (Castagnone-Sereno, 2012). Aggressiveness is the ability of the nematode to invade and reproduce in a suitable host (Shaner et al., 1992).

The host range of $M$. enterolobii includes several species of crop plants of great economic importance as pepper, tomato, soybean, guava, coffee, beans, watermelon and potato among others (Moens et al., 2009). This species has the ability to successfully establish themselves in genotypes of plants carrying dominant genes conferring resistance to the three major species of RKNs on tomato (Mi-1), potato (Mh), soybeans (Mir1) and pepper ( $N$ and Tabasco) (Castagnone-Sereno, 2012). Meloidogyne enterolobii has been detected in Africa, Europe, USA, Central and South America (Brito et al., 2007; Moens et al., 2009; Castagnone-Sereno, 2012); and recently was first reported in Mexico parasitizing watermelon (Veracruz state) and tomato plants (Sinaloa state) (Ramirez-Suarez et al., 2014; Martinez et al., 2015); however, its presence in other crops and in other regions is unknown. In the present research, we report the presence of this nematode in Jalapeño pepper collected in the state of Sinaloa. 


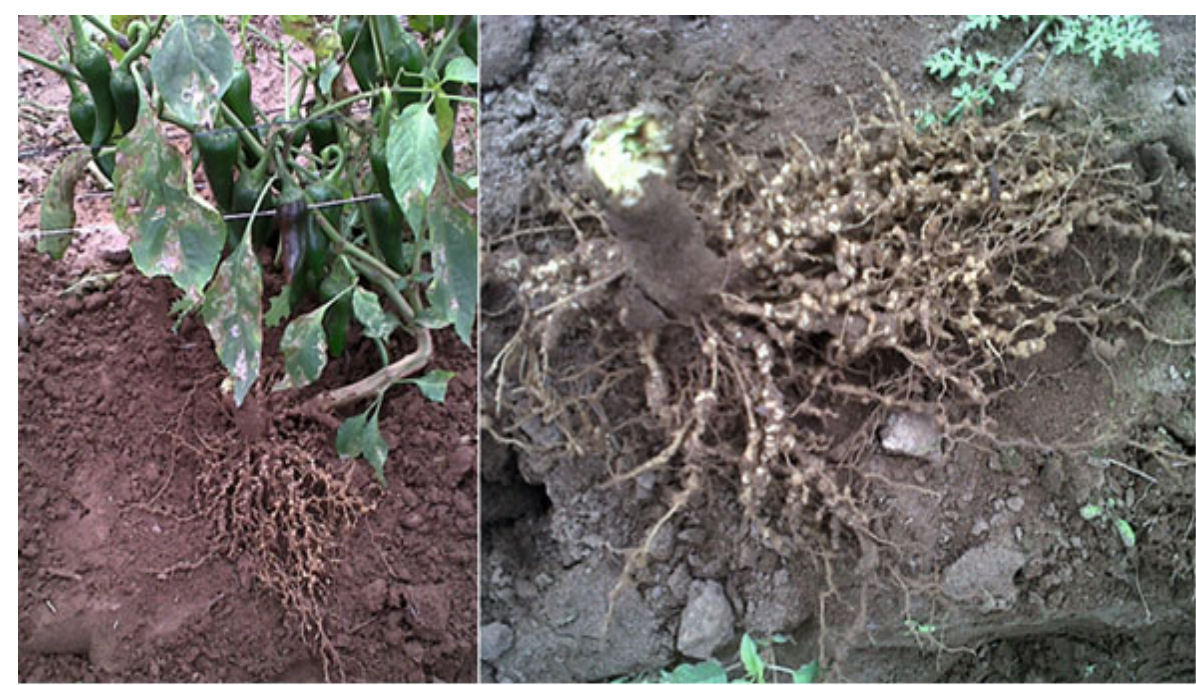

Fig. 1. Jalapeño pepper roots severely galled by Meloidogyne spp.

\section{Materials and Methods}

\section{Biological material}

In the municipality of Ahome, Sinaloa, Mexico ( $25^{\circ} 58^{\prime} 33.86^{\prime \prime}$ $\mathrm{N}$ and $\left.109^{\circ} 09^{\prime} 21.04^{\prime \prime} \mathrm{W}\right)$, in December 2011, root samples of chilli pepper (cv. Jalapeño) heavily galled were collected (Fig.1). Eggs were extracted according to Vrain (1977) and incubated at $28 \pm 1^{\circ} \mathrm{C}$ in Petri dishes containing sterile distilled water to obtain the second-stage juveniles $\left(\mathrm{J}_{2}\right)$. Mature females were obtained by dissecting root galls. The nematode population was increased on tomato plants (cv. Rio Grande) maintained in the greenhouse (Colegio de Postgraduados Campus Montecillo).

\section{Morphological identification}

The second-stage juveniles $\left(\mathrm{J}_{2}\right)$ and adult females were used. The process of fixation, dehydration and the mounting of $\mathrm{J}_{2}$ was performed according to Seinhorst (1959) and to Cid del Prado Vera and Subbotin (2012); whereas the perineal patterns were prepared according to Riggs (1990). The observations and measurements of the preparations were carried out under a phase contrast microscope (Olympus BX41, Japan) equipped with a digital camera (Big Catch AM-423X, China). Morphological and morphometric identification was performed according to the original description of the species M. enterolobii (Yang \& Eisenback, 1983; Rammah \& Hirschmann, 1988) based on the distinctive characteristics of RKNs species, such as perineal pattern morphology and head of adult females; and body length, tail and hyaline region of $\mathrm{J}_{2}$ (EPPO, 2011).

\section{Molecular identification}

Genomic DNA extraction. Second-stage juveniles $\left(\mathrm{J}_{2}\right)$ were concentrated by centrifugation at $3000 \mathrm{rpm}$ for $5 \mathrm{~min}$, and the supernatant was discarded. The precipitated pellet in Eppendorf tubes was frozen with liquid $\mathrm{N}_{2}$ and macerated using a micropestle. The macerate was homogenized with $250 \mu \mathrm{L}$ of extraction buffer [(500 $\mathrm{mM} \mathrm{KCl}, 100$ mM Tris HCl pH 8.0, 1 \% Tritón X-100, 400 mg/mL Proteinase $\mathrm{K}$ (Sigma-Aldrich $\left.{ }^{\circledR}\right)$ ], and then this mixture was incubated at $60{ }^{\circ} \mathrm{C}$ for $4 \mathrm{~h}$ and the end at $90^{\circ} \mathrm{C}$ for $10 \mathrm{~min}$ to inactivate the Proteinase K. Subsequently, the mixture was centrifuged at $5000 \mathrm{rpm}$ for $5 \mathrm{~min}$, the supernatant was placed in a new tube adding $600 \mu \mathrm{L}$ of chloroform: isoamyl alcohol (24:1) and the new mixture was centrifuged at $10000 \mathrm{rpm}$ for $10 \mathrm{~min}$. The DNA was then precipitated by adding $100 \mu \mathrm{L}$ isopropanol and incubating for $30 \mathrm{~min}$ at $-20^{\circ} \mathrm{C}$; then was centrifuged at $10000 \mathrm{rpm}$ for $10 \mathrm{~min}$, the pellet was washed with $1 \mathrm{~mL}$ of $70 \%$ ethanol (10 $000 \mathrm{rpm}$ for $10 \mathrm{~min}$ ), dried at room temperature and resuspended in $30 \mu \mathrm{L}$ of nuclease-free water.

\section{Polymerase chain reaction.}

PCR was performed using sequence-characterized amplified region (SCAR) specific primers: MK7-F (5'-GATCAGAGGCGGGCGCATTGCGA-3') and MK7-R (5'-CGAACTCGCTCGAACTCGAC-3') ( 520 pb) (Tigano et al., 2010). rDNA-IGS2 (intergenic spacer region 2) was amplified using specific primers Me-F (5'-AACTTTTGTGAAAGTGCCGCTG-3') and Me-R (5'-TCAGTTCAGGCAGGATCAACC-3') ( 236 pb) (Long et al., 2006). The reaction mixture consisted of: buffer $10 \mathrm{X} ; 1.5 \mathrm{mM} \mathrm{MgCl}_{2} ; 0.2 \mathrm{mM}$ dNTPs, amplificase (Biotecmol); $0.12 \mu \mathrm{M}$ of IGS2 primers (Me-F/Me-R or SCAR MK7-F/MK7-R); $1 \mu \mathrm{L}$ DNA and nuclease-free water to a final volume of $25 \mu \mathrm{L}$. PCR amplification conditions consisted of an initial denaturation at $94^{\circ} \mathrm{C}$ for 2 min followed by 35 cycles at $94{ }^{\circ} \mathrm{C}$ for $30 \mathrm{~s}$, annealing at $68^{\circ} \mathrm{C}$ for $30 \mathrm{~s}, 72^{\circ} \mathrm{C}$ for $30 \mathrm{~s}$, and a final extension at $72^{\circ} \mathrm{C}$ for $5 \mathrm{~min}$.

PCR products were separated by electrophoresis in a $1 \%$ agarose gel stained with ethidium bromide; and were purified with QIAquick ${ }^{\text {TM }}$ PCR purification Kit (Qiagen) according to the manufacturer's instructions and sequenced to confirm their identity. IGS2 PCR product was sequenced in both directions with IGS2 primers, 
whereas the SCAR amplicon was in one direction (MK7-F). The IGS2 sequences were processed using the BioEdit software (version 7.2.5) to obtain a consensus sequence. Nucleotide sequences were aligned using BLAST (National Center for Biotechnology Information).

\section{Results}

\section{Morphological identification}

The morphological and morphometric characteristics of the sec- ond-stage juveniles $\left(\mathrm{J}_{2}\right)$ and mature females of studied population of RKN were similar to those reported in the original description of M. enterolobii (M. mayaguensis) (Yang \& Eisenback, 1983; Rammah \& Hirschmann, 1988). The tail of $\mathrm{J}_{2}$ was relatively thin, long and rounded end portion and with hyaline region, and sometimes with a lobed terminus (Fig. 2A and 2B).

Measures and ratios corresponded to those reported in the literature. Thus, the average body length was $414.5 \pm 22.9 \mu \mathrm{m}$ and an average body width of $14.05 \pm 0.7 \mu \mathrm{m}$. The average length stylet $11.3 \pm 0.8 \mu \mathrm{m}$ and an average distance of DGO (dorsal esopha-

Table 1. Morphometry of second-stage juveniles and adult females from chilli pepper (cv. Jalapeño) compared with previous data of $M$. enterolobii described in the literature.

\begin{tabular}{|c|c|c|c|}
\hline \multirow[t]{3}{*}{ Character } & This work & Yang and Eisenback, 1983 & Rammah and Hirschmann, 1988 \\
\hline & \multicolumn{3}{|c|}{ Second-stage juveniles $\left(\mathrm{J}_{2}\right)$} \\
\hline & $n=28$ & $n=30$ & $\mathrm{n}=35$ \\
\hline Body length & $\begin{array}{c}414.5 \pm 22.9^{\#} \\
(391.5-486.8)\end{array}$ & $\begin{array}{c}436.6 \pm 16.61 \\
(405-472.9)\end{array}$ & $\begin{array}{c}453.6 \pm 28.4 \\
(390.4-528.0)\end{array}$ \\
\hline Greatest body width & $\begin{array}{c}14.05 \pm 0.7 \\
(13.2-15.6)\end{array}$ & $\begin{array}{c}15.3 \pm 0.89 \\
(13.9-17.8)\end{array}$ & $\begin{array}{c}14.7 \pm 0.5 \\
(13.8-15.8)\end{array}$ \\
\hline Stylet length & $\begin{array}{c}11.3 \pm 0.8 \\
(10.1-13.0)\end{array}$ & $\begin{array}{c}11.7 \pm 0.45 \\
(10.8-13.0)\end{array}$ & $\begin{array}{c}11.6 \pm 0.3 \\
(11.1-12.2)\end{array}$ \\
\hline DGO & $\begin{array}{c}3.4 \pm 0.4 \\
(2.6-4.2)\end{array}$ & $\begin{array}{l}3.4 \pm 0.33 \\
(2.8-4.3)\end{array}$ & $\begin{array}{c}3.9 \pm 0.2 \\
(3.3-4.3)\end{array}$ \\
\hline Tail length & $\begin{array}{c}54.4 \pm 5.5 \\
(40.7-61.6)\end{array}$ & $\begin{array}{c}56.4 \pm 4.48 \\
(41.5-63.4)\end{array}$ & $\begin{array}{c}54.4 \pm 3.6 \\
(49.2-62.9)\end{array}$ \\
\hline Hyaline region length & $\begin{array}{c}14.2 \pm 0.8 \\
(11.5-15.0)\end{array}$ & -------- & ------ \\
\hline a & $\begin{array}{c}29.5 \pm 1.6 \\
(26.3-33.5)\end{array}$ & $\begin{array}{c}28.6 \pm 1.88 \\
(24.0-32.5)\end{array}$ & $\begin{array}{c}30.9 \pm 1.9 \\
(26.4-34.7)\end{array}$ \\
\hline \multirow[t]{3}{*}{ c } & $\begin{array}{c}7.9 \pm 0.7 \\
(6.4-9.6)\end{array}$ & $\begin{array}{c}7.8 \pm 0.65 \\
(6.8-10.1)\end{array}$ & $\begin{array}{c}8.3 \pm 0.4 \\
(7.0-9.2)\end{array}$ \\
\hline & & Females & \\
\hline & $n=8$ & $n=20$ & $n=35$ \\
\hline Stylet length & $\begin{array}{c}14.5 \pm 1.7 \\
(12.8-17.3)\end{array}$ & $\begin{array}{c}15.1 \pm 1.35 \\
(13.2-18.0)\end{array}$ & $\begin{array}{c}15.8 \pm 0.8 \\
(13.8-16.8)\end{array}$ \\
\hline DGO & $\begin{array}{c}4.7 \pm 1.1 \\
(3.2-6.4)\end{array}$ & $\begin{array}{l}4.9 \pm 0.78 \\
(3.7-6.2)\end{array}$ & $\begin{array}{c}4.8 \pm 0.8 \\
(3.5-6.7)\end{array}$ \\
\hline Vulva-anus distance & $\begin{array}{c}18.5 \pm 1.0 \\
(17.4-19.6)\end{array}$ & $\begin{array}{c}22.2 \pm 1.76 \\
(19.7-26.6)\end{array}$ & $\begin{array}{c}18.4 \pm 1.5 \\
(12.7-21.1)\end{array}$ \\
\hline Vulval slit length & $\begin{array}{c}23.5 \pm 1.9 \\
(20.2-25.3)\end{array}$ & $\begin{array}{c}28.7 \pm 1.96 \\
(25.3-32.4)\end{array}$ & $\begin{array}{l}26.1 \pm 1.9 \\
(20.9-30.4)\end{array}$ \\
\hline
\end{tabular}

\#Average measurements in $\mu \mathrm{m} \pm$ standard deviation (range) a: body length/greatest body width, $c$ : body length/tail length DGO: dorsal esophageal gland orifice 


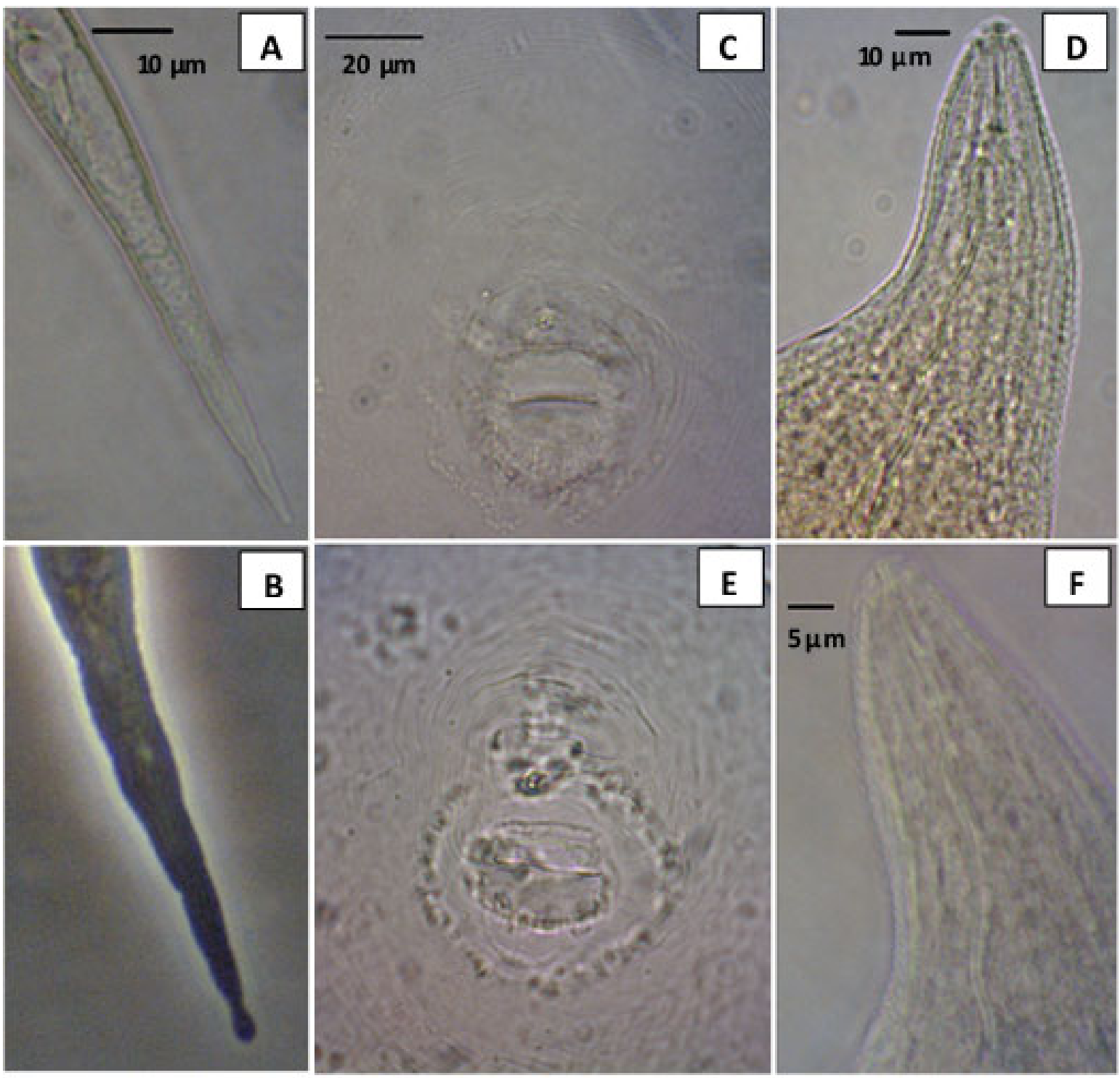

Fig. 2. M. enterolobii. Second-stage juveniles $\left(\mathrm{J}_{2}\right)$ : Tail region $(A)$, tail terminus $(B)$. Adult females: perineal patterns $(C$ and $E)$, necks $(D$ and $F)$

geal gland orifice) to the stylet base of $3.4 \pm 0.4 \mu \mathrm{m}$. The average tail length was $54.4 \pm 5.5 \mu \mathrm{m}$ and an average hyaline region 14.2 $\pm 0.8 \mu \mathrm{m}$. The average of body length/greatest body width (index a) was $29.5 \pm 1.6$; and the body length/tail length (index c) was $7.9 \pm 0.7$ (Table 1). Adult females showed a perineal pattern of oval shape, dorsal arch usually high and round, weak lateral lines sometimes present, large phasmids (Fig. 2C and 2E), typical characters of the species $M$. enterolobii. Also showed a lip region not annulated and an elongated neck (Fig. 2D and 2F). The average stylet length was $14.5 \pm 1.7 \mu \mathrm{m}$, the average distance of DGO to the stylet base was $4.7 \pm 1.1 \mu \mathrm{m}$, the average vulva-anus distance was $18.5 \pm 1.0 \mu \mathrm{m}$, and average vulva slit length was 23.5 $\pm 1.9 \mu \mathrm{m}$ (Table 1).

\section{Molecular identification}

PCR amplification was positive with SCAR and IGS2 specific primers, where in both cases a single fragment was observed (Fig. $3 \mathrm{~A}$ and $3 \mathrm{~B}$ ).

DNA sequencing analysis of the PCR products, and subsequent alignment using the BLAST program indicated that the fragment generated with Me-F/Me-R primers exhibited $99 \%$ identity with rDNA IGS2 sequences of $M$. enterolobii (Accession numbers: KM008548, JN005846, GQ395554, GQ395547, GQ395531GQ395533, and GQ395524). The fragment generated with the SCAR primers (MK7-F/MK7-R) showed $99 \%$ identity with the MK7-SCAR sequence of M. enterolobii (supplied by Dr. Valdir Correa and Dr. Regina Carneiro. Embrapa Recursos Genéticos e Biotecnologia, Brazil). 


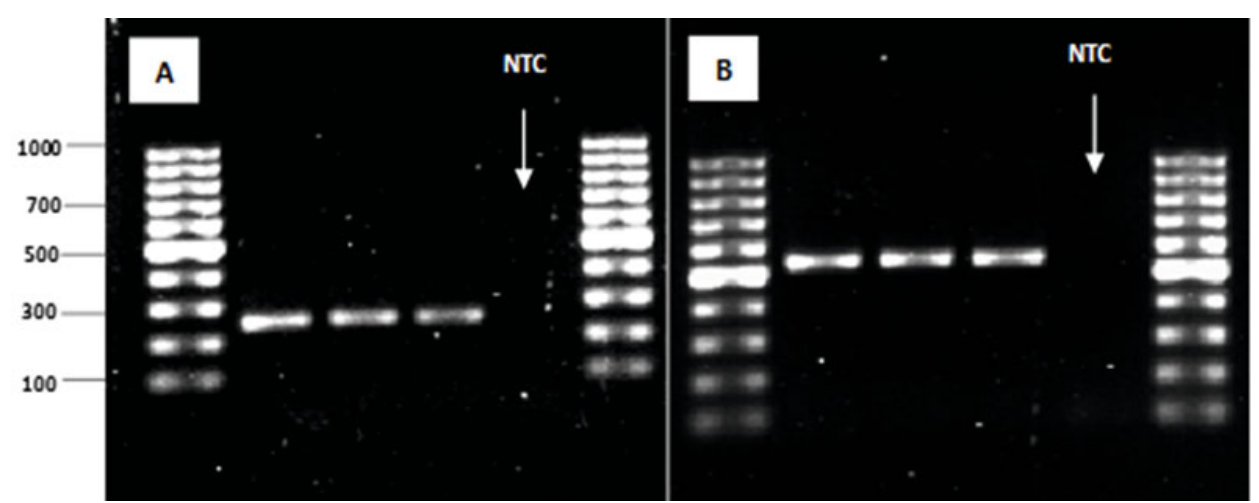

Fig. 3. Fragments amplified from DNA of second-stage juveniles $\left(\mathrm{J}_{2}\right)$ using M. enterolobii-specific primers: IGS2 Me-F/Me-R ( 236 pb) (A) and SCAR MK7-F/MK7-R ( $520 \mathrm{pb})$ (B). NTC: negative control without DNA template. 100-pb ladder (Fermentas ${ }^{\mathrm{TM}}$ )

\section{Discussion}

Meloidogyne enterolobii (=M. mayaguensis) is an emerging species, and due to its wide host range is considered to be polyphagous. It is further characterized by its remarkable pathogenicity to overcome resistance to $M$. incognita, $M$. arenaria and $M$. javanica in pepper and tomato genotypes (Brito et al., 2007; Castagnone-Sereno, 2012). The increasing geographical distribution of M. enterolobii threatens the production of crops that are of economic importance worldwide. In Mexico, the state of Sinaloa ranks first in tomato and green pepper and second in potato production, these vegetable crops are potential hosts of $M$. enterolobii (SIAP, 2013). In the present study, the presence of $M$. enterolobii parasitizing chilli pepper plants (cv. Jalapeño) in Sinaloa, Mexico was confirmed. Morphometric characters of second-stage juveniles $\left(\mathrm{J}_{2}\right)$ and adult females usually were within the range reported in the original description of this species (Yang \& Eisenback, 1983; Ramma \& Hirschmann 1988). A peculiarity of $J_{2}$ of $M$. enterolobii is the body length $(405-472.9 \mu \mathrm{m})$, which is larger than that of M. incognita $(360-393 \mu \mathrm{m})$ (Yang \& Eisenback, 1983). In addition to this, the $\mathrm{J}_{2}$ have a greater length of the tail compared to the species M. incognita $(46 \mu \mathrm{m}), M$. javanica $(49 \mu \mathrm{m})$ and $M$. hapla $(43 \mu \mathrm{m})$, but very close to the value of $M$. arenaria (55.8 $\mu \mathrm{m})$ (EPPO, 2011). In our case, the average value of the tail was $54.4 \mu \mathrm{m}$ very close to the populations of $M$. enterolobii from China (Yang \& Eisenback, 1983) and M. mayaguensis from Costa Rica (Ramma \& Hirschmann, 1988). Perineal patterns showed a dorsal arch rounded which is typical of $M$. enterolobii, and usually sets it apart from the common species $M$. incognita, $M$. arenaria, $M$. javanica and $M$. hapla (EPPO, 2011). It should be mentioned that it is not unusual that overlaps occur between the values of the different species of root-knot nematodes. Such situations do not allow a correct differentiation between these species, so the use of more than one identification technique is necessary, as was carried out for the population we analyzed.

Molecular analysis of the DNA amplified fragments of $\sim 236$ and $\sim 520$ bp obtained by using IGS2 and SCAR primers, respectively, revealed that they corresponded to those reported (Long et al., 2006; Tigano et al., 2010). The percentages of similarity of the IGS2 amplicon with the corresponding sequences found in Genbank (NCBI) were high (99\%), whereas for the SCAR amplicon ( $\sim 520 \mathrm{bp}$ ) no corresponding sequences were found in the database. The reason for this is that in such database SCAR sequences of this species have not been registered yet; however, the amplicon obtained exhibited $99 \%$ similarity to the sequence SCAR-MK7 supplied by the researchers who designed the primers specific for M. enterolobii (Tigano et al., 2010; Correa \& Carneiro, personal communication). The results obtained in this research indicate that the root-knot nematode present in Ahome, Sinaloa, corresponds to $M$. enterolobii. To our knowledge, this is the first report of $M$. enterolobii in chilli pepper in this region of Mexico, considered one of the vegetable crop areas of major economic importance.

\section{Acknowledgements}

We thank the National Council on Science and Technology (CONACYT) for the scholarship granted to the first author. We also thank the MSc. J. A. Garcia-Espinoza for supporting the collection of samples of diseased plant material in the study region (Sinaloa, Mexico).

\section{References}

Adams, B.J., Dillman, A.R., Finıinson, C. (2009): Molecular taxonomy and phylogeny. In: PerRY, R. N., Moens, M., StarR, J. L. (Eds). Root-knot nematodes. CAB International, Wallingford, UK., pp. $119-138$

Brito, J.A., Stanley, J.D., Kaur, R., Cetintas, R., Di Vito, M., Thies, J.A., Dickson, D.W. (2007): Effects of the Mi-1, $N$ and Tabasco genes on infection and reproduction of Meloidogyne mayaguensis on tomato and pepper genotypes. J. Nematol., 39: 327 - 332

Castagnone-Sereno, P. (2012): Meloidogyne enterolobii (=M. mayaguensis): profile of an emerging, highly pathogenic, rootknot nematode species. Nematology, 14: 133 - 138. DOl: $10.1163 / 156854111 \times 601650$ 
Cid Del Prado Vera, I., Subbotin, S.A. (2012): Belonolaimus maluceroi sp. n. (Tylenchida: Belonolaimidae) from a tropical forest in Mexico and key to the species of Belonolaimus. Nematropica, 42: $201-210$

EPPO (2011): Meloidogyne enterolobii. European and Mediterranean Plant Protection Organization Bulletin OEPP/EPPO, 41: 329 - 339. DOI: 10.1111/j.1365-2338.2011.02497.x

LoNG, H., LIU, H., XU, J.H. (2006): Development of a PCR diagnostic for the root-knot nematode Meloidogyne enterolobii. Acta Phytopathol. Sin., 36: 109 - 115

Martínez, G.J.A., Díaz, V.T., Allende, M.R., García, E.R.S., CarrilLO, F.J.A. (2015): Primer reporte de Meloidogyne enterolobii parasitando tomate en Culiacán, Sinaloa, México. Rev. Mex. Cienc. Agric., 11: $2165-2168$

Moens, M., Pery, R.N., StarR, J.L. (2009): Meloidogyne species-a diverse group of novel and important plant parasites. In: PERRY, R.N., Moens, M., StarR, J.L. (Eds.). Root-knot nematodes. CAB International, Wallingford, UK., pp: 1 - 17

Ramirez-Suárez, A., Rosas-Hernández, L., Alcasio-Rangel, S., Powers, T.O. (2014): First report of the root-knot nematode Meloidogyne enterolobii parasitizing watermelon from Veracruz, México. Plant Dis., 98: 428. DOI: 10.1094/PDIS-06-13-0636PDN

Rammah, A., Hirschmann, H. (1988): Meloidogyne mayaguensis n. sp. (Meloidogynidae), a root-knot nematode from Puerto Rico. J. Nematol., 20: $58-69$
RIGGS, R.D. (1990): Making perineal patterns of root-knot nematodes and vulval cones of cyst nematodes. In: ZUCKERMAN, B. M., MAl, W.F., KRUSBERG, L.R. (Eds) Plant Nematology Laboratory Manual. University of Massachusetts Agricultural Experiment Station, Amherst, Massachusetts, pp: 103 - 106

Shaner, G., Stromberg, E.L., Lacy, G.H., Barker, K.R., Pirone, T.P. (1992): Nomenclature and concepts of pathogenicity and virulence. Annu. Rev. Phytopathol., 30: 47 - 66. DOI: 10.1146/annurev.py.30.090192.000403

SEINHORST, J.W. (1959): A rapid method for transfer of nematodes from fixative to anhydrous glycerin. Nematologica, 4: $67-69$. DOI: 10.1163/187529259X00381

SIAP. (2013): Servicio de Información Agroalimentaria y Pesquera. SAGARPA. http://www.siap.gob.mx/

Tigano, M., De Siqueira, K., Castagnone-Sereno, P., Mulet, K., QueIROZ, P., Dos Santos, M., Teixeira, C., Almeida, M., Silva, J., CarnelRO, R. (2010): Genetic diversity of the root-knot nematode Meloidogyne enterolobii and development of a SCAR marker for this guava-damaging species. Plant Pathol., 59: 1054 - 1061. DOI: 10.1111/j.1365-3059.2010.02350.x

VRAIN, T.C. (1977): A technique for the collection of larvae of Meloidogyne spp and a comparison of eggs and larvae as inocula. $J$. Nematol., 9: 249 - 251

YANG, B., EISENBACK, J.D. (1983): Meloidogyne enterolobii n. sp. (Meloidogynidae), a root-knot nematode parasitizing pacara earpod tree in China. J. Nematol. 15: 381 - 391 